\title{
Understanding of Wellbeing through Ancient Indian Spiritual Texts
}

\author{
Srinivas Arka \\ PhD Candidate, International University of Professional Studies (IUPS), Maui, Hawaii, USA
}

\begin{abstract}
This paper introduces some aspects of the Indian philosophy and the spiritual quest, which can be seen as leading to 'ultimate wellbeing' and 'ultimate wellness' for it involves how to live a most meaningful yogic life in full clarity and with respect to all that exists around oneself. Indian spirituality, as depicted in the Vedas and resumed in the Bhagavad-Gita, also embraces and guides as to how to live both a material and spiritual life in parallel and at some point, dropping the material tendency and embracing spiritual enlightenment. Additionally, this paper outlines how Indian spirituality is also unusual in that there are followers of three underlying philosophies of Advaita, Dvaitha and Vishistadvaita that live side by side and these three traditions do not attempt to dominate each other. In this sense, tolerance and harmonious co-existence seem to be the basis of the Indian philosophic system, which also spills over into everyday life.
\end{abstract}

Keywords Bhagavad-Gita, Vedas, Indian Spirituality, Wellness, Yoga, Indian Philosophy

\section{Introduction}

We live in a world where everything is measured. A measure of water to quench one's thirst, a pinch of salt to make the food palatable, and a measure of food to satiate one's hunger. This can go on. Even a level of happiness to relieve oneself from sadness. We live in a world where happiness is being measured too and is being equated to wellness and wellbeing. By wellbeing, I suggest conditions beyond one's primordial satisfactory existence, even beyond a level of prosperity or wealth which may be construed as part of the world happiness index ${ }^{1}$. Economists including behavioural economists concerned largely with GDP growth and such other variable appear to

1 Gallup, Inc. (n.d.). Gallup 2018 Global Emotions Report. Retrieved from

https://www.gallup.com/analytics/241961/gallup-global-emotions-report -2018.aspx.

ISSN: 2332-6840 (Online) 2332-6832 (Print) Copyright (C) 2018 by authors, all rights reserved. Authors agree that this article remains permanently open access under the terms of the Creative Commons Attribution License 4.0 International License see six key variables constituting their definition of well-being: (1), income, (2), healthy life expectancy, (3), social support, (4), freedom, (5), trust and (6), generosity (Helliwell et al, 2018). One needs to wonder how the last three variables such as freedom, trust and generosity have been measured only through economic criterion. Gallup Polls for instance deploys life satisfaction scales that let people score their daily experiences. Experiences of feelings when they are well rested; being treated with respect; feeling that are evoked when they smile or indulge in laughter; feelings associated with learning new things; pursuing interests; hobbies and finally feelings that arise out of enjoyment, etc. But they also add variables such as feelings evoked by physical pain, worry, sadness, stress and anger. The daily experiences in their survey were scored dichotomously with higher scores representing better days. Happiness is not a synonym of wellbeing, ironically there is a tendency to use them interchangeably (Tandon, 2016). It is equally important to consider that wellbeing as seen in Eastern collectivist societies, once again differs from the pronounced individualistic orientation that prevails in the West. Although the Western influence is pervasive the understanding of and pursuit of wellness from a nonmaterial perspective is still prevalent in the Eastern societies. Furthermore, the notions and ideas contained in 'ultimate wellbeing' are different from perceptions of happiness however accurate they researchers may have seen or measured in happiness studies. There is that 'inward looking' in the 'ultimate wellbeing' that gradually upgrades one's existence from the world of material to the realm of the spiritual. I will endeavor to explain wellbeing from the above contexts.

In this paper I look at the relationship between the Bhagavad-Gita and the Vedas, which together with the Upanishads, forms the basis of Indian Spirituality. I suggest that Indian Spirituality is also about understanding oneself in relation to the others in the society as well. Thus the insights that one gains by examining oneself allows one to gain a better grip or control on themselves and will allow them to think of more virtuous behaviour towards others. A contended life that merely requests adequate resources to 
fulfill one's responsibilities not only to his or her immediate family but for all those around him or her is associated with the craving for wellbeing in a very socio centric way. There is no self or ego involved in this craving, once again coming closer to the concepts of the Eastern collectivist philosophy. Again, social practice in ones' daily life and through the practice via Dhyana or deep sincere meditation, assist one to reach the higher level or enlightened state of consciousness. This for me is "ultimate wellbeing". When people look at half empty glass or half full, a thought that doesn't arise quickly to them, that it is not about two halves actually that are about an attitude of the mind and not a litmus test. On the contrary it is an expression of one's world view that 'a balanced culture should bring the two halves into harmony' (Radhakrishnan, 1974, p.7).

\section{Mahabharath and the Bhagavad-Gita}

The Bhagavad Gita also know as the Gita, has influenced China and Japan and latterly to the lands in the west (Radhakrishnan, 1974). The two chief works of Mahayana Buddhism, Mahayanasraddhoppatti (the awakening of faith in the Mahayana) and Saddharmapundarika (The Lotus of the True Law) are deeply indebted to the teaching of Gita ( Radhakrishnan, 1974). J.W.Hauer, a Sanskrit scholar who served as a missionary in India called it a testimony of Indo Germanic religious history and stated the importance of the central message of Gita as:

"We are not called to solve the meaning of life but to find out the deed demanded of us and to work and so, by action, to master the riddle of life" 2

The great epic depicting the end of age of Mahabharath is considered by scholars as the fifth Veda because of its magnanimity and vast volume which also comprises almost all matters related to human life and enquiry as well as the complexities of existence itself (Pattanaik (2015). Krishna the leading figure of Mahabharath epic is depicted as being on a battle field just before the outbreak of a war. On being sincerely approached by Arjuna his disciple and relative, Krishna uses the seeker as an instrument to pass on the essence of Vedas in his words of advice and admonition to Arjuna. Vyasa Maharshi captured their conversation. This epic later became known as Bhagavad Gita. This work also reflects the Upanishads for the Upanishads are considered as stairways to Veda. One can also relate the Bhagavad-Gita to the Upanishads as it is concerned with suggestions and guidance as how to live life and find spiritual development of the inner self.

Bhagavad-Gita represents the core-essence of Veda. Krishna employs words like Divya Chakshu. This refers to

2 Hauer, J, W. (1940), Hibbert Journal, April, 1940, p.341.) quoted by Radhakrishnan, Sarvepalli, (1974) in his introductory essay. a special eye, which all humans have between temples. When this eye is open, the person is said to see beyond the physical and recognise the light of consciousness within it. It is referred to the 'cosmic divine eye'. Vishwaroopa Darshana involves envisioning the whole universe in an elevated meditational attainment. In addition many forms of Yoga referred to in the Vedas, are also referred to in the Bhagavad-Gita. Due to this additional evidence, all Vedic scholars, without exception agree that the Bhagavad-Gita is a condensed form of Veda.

\section{The message of the Bhagavad-Gita}

The main message of Bhagavad Gita is how to live a most meaningful yogic life in full clarity and with respect to all that exists; how to live both - material and spiritual life in parallel and at some point, dropping the material tendency and embracing spiritual aspect. It also involves gaining the knowledge of your own soul with which one can understand and experience the world as One in all and all in One. In addition, the core message of Bhagavad Gita is that all of us are born yogis. When this is realised, enlightenment unfolds. The ultimate purpose of humans should be to attain salvation from the cycles of birth and death. Karma is the account of all humans thinking, saying and acting. By altering these one can reduce negative karmic effects and find immense peace and progress in many spheres of human activity.

\section{Altering One's Karma}

The Bhagavad Gita as said earlier, opens with a problem, that is, Arjuna refuses to fight the war and raises innumerable objections. He puts a plausible plea for abstention from activity of war and for him to retreat from the world, which was an accepted ideal of the times of Mahabharath. Arjuna appears to be the seeker of perfection, and is found in the opening sections of the Bhagavad-Gita with his 'mind clouded, his conviction unsettled, his consciousness confused' (Radhakrishnan, 1974, p.51).

This became the purpose of Gita to convert Arjuna to action rather than renunciation, thus the teacher in this context - Krishna 'does not dismiss the world as an illusion and action as a snare. He recommends the full active life of a man in the world with the inner life anchored in the eternal spirt'. (Radhakrishnan, 1974, p 66). The Bhagavad Gita therefore is a mandate for action. It sets out to clarify what a man ought to do not merely as a social being but as an individual with a spiritual destiny. Following such a view all material realities there are also the Laws of karma in Nature that are fixed and universal. That is how everything works. It is also like gravitation field of the earth. All living species and entities come under the influence of gravity, so also karma cannot be escaped. 
Karmas are produced by our thoughts and minds. Engaging in action is the after effect of those thoughts. If a person is in a coma, there is no karma. Also when you are engaged in deep sincere meditation or Dhyana no karma is performed. During sleep there is also no karma.

Gandhi explained Negative Karma in a profound yet simple manner. 'A man is but product of his thoughts. What he thinks, he becomes' ${ }^{3}$. Negative karma is what brings negative results back, so positive karma brings positive results in return. Everything will return and resound from nature. It is like a boomerang that reaches the person or the place where it was sent into the air (Sri Ramakrishna Math, 2006).

A secret spelt out by Krishna, is to do karma (action) without focusing on the results and not to be attached to them either. Then the performer of karma (action while doing duty) remains unaffected by karmic return effect. Clearly, the chain of karma can be broken here and now in this world without the flux of the empirical world. One becomes a master of karma by developing that detachment (Radhakrishnan,1974). A secondary way is to do more positive karmas to dilute negative karma imprinted on human brains and minds and also in their bodies. Whenever possible the person is encouraged to be occupied in Dhyana as during that period of Dhyana (meditation) the meditator remains unaffected by any karma of the world or himself. Gaining true knowledge can burn away some impressions of karmas stored in the subliminal mind and deeper brains as knowledge is like fire. Such knowledge can also be called Atma Jnana or knowledge of the inner self or the soul. To a degree, one can alter one's karma by practicing forgiving nature, seeing the best in others, turning negative thinking and energies into positivity by changing one's thoughts, repeating some mantras of one's choice and experimenting with the effect of them.

Bhagavad Gita is one of the greatest spiritual works because it cannot be narrowed down to limited prescriptions and preaching Additionally, it opens up widely and embraces many different options such as Samkya yoga, Karma Yoga, Bhakthi Yoga, Jnana Yoga etc.

Bhagavad Gita provides freedom to choose one's path of life, being practical and even rational as much as it is spiritual.

\section{Yoga as told in Bhagavad-Gita}

Yoga is branded in modern times as observing asanas. However the real meaning is much deeper than is generally understood today. It is the path of life or having firm control over oneself or have complete self-possession. True yoga is a disciplined activity and is considered as

3 10 Leadership lessons I learned from Mahatma Gandhi. (2011, July 18). Retrieved from http://ioanneconstantino.wordpress.com/2011/07/18/10-leadership-lesso ns-i-learned-from-mahatma-gandhi/ good as renunciation, or Sanyasa (Radhakrishnan,1974). By practicing and adopting it in daily life, one can enjoy the benefits of life and on inquiring deeply, one can attain higher awareness. Yoga allows assists in divesting our minds of all sensual desires, abstracts out attention from all external objects and allows us to absorb it in the object of meditation- (ekaagrena (with concentrated) cetasaa (with mind). ${ }^{4}$

As per the Bhagavad Gita, there are three major paths of yoga (Yadav,2009):

- Karma Yoga (performing actions without being attached, especially to the fruit of their results)

- Bhakthi Yoga (surrendering ego and enhancing emotional expression to creation, with love, sincerity and dedication)

- Janana Yoga (this path of Yoga is epistemological in nature; it involves managing mind, finding clarity, removing fear, disbeliefs, doubts and questions raising conscious awareness of one's inner self and outer self).

The Bhagavad-Gita is an inspiration for me as a Yogi, as, as an ambassador of the world, one can ascend to heights of conscious awareness and do many good things for the world based on unconditional service. This involves considering everything and everyone as part of you. By being close to one's spirit, one can remain timeless and gain strength through working with nature thereby gaining inspirations and reflections. As one has the universe reflecting within, knowing the inner self means knowing many things regarding outside nature as well. (Times group, n.a, 2015). The message of the Bhagavad-Gita is not only about understanding, but via Dhyana one could reach the enlightened state of consciousness. Through this a Yogi can see and experience unity in diversity. A new reader of Bhagavad-Gita should approach as though he or she is Arjuna caught between the war and peace. Therefore knowing a little about the background of Arjuna prior to coming to the battlefield would be a good idea. Also, rather than reading it as a scripture representing any culture, considering it as a great dialogue between the two personalities, one humble and receptive, and the other enlightened and giving, is a good way to start (Bhaktivedanta Swami Prabhupada, 2008).

\section{The Vedas}

The primary meaning of Veda is Knowledge. Knowledge is of two kinds. The first type of knowledge is derived from the sense organs and is authenticated by a variety of evidence. This is the form of knowledge that

4 The teacher, Charioteer Krishna asks Arjuna: "Has the delusion of thy ignorance been destroyed "This: What I have told thee. have you heard it? O Arjuna? with one-pointed mind Have you grasped My teaching Delusion of ignorance: The absence of discrimination which is caused by ignorance and which is natural. The destruction of delusion is the aim of all this endeavour on your part to hear the scripture and the exertion on My part as the teacher. 
falls in the realm of physical sciences. The second, type of knowledge is transcendent and is realised through the mental and spiritual discipline of yoga. According to Yogi Ashokananda (2015), scholars place the date of composition of the Bhagavad-Gita between the fifth and the second centuries BCE and the Vedas around $1500 \mathrm{BCE}$ to $1000 \mathrm{CE}$.

The Vedas are called Shruthi meaning, Truths cascaded and sounded in the hearts and souls of Rishis or Seers also called Dhrishtas who were absorbed in deep meditative states or Tapasya. What they heard intuitively in their souls, were later expressed in the form of verses which they themselves were often unaware of the real meanings. The collection of these verses referred to as the Vedas and are said to come direct from cosmic being. The Vedas, deluge of higher most inspiring wisdom, were later complied into four parts by the sage Veda Vyasa (his original name was Krishna Dwaipayana) who was said to know them well. The Vedas were organised by Vyasa according to their subject matter: the Rig (hymn), Yajur (ritual) and Sama (melody) (Pattanaik, 2015). The Atharvana Veda, on the other hand, is projected to the sages Angiras and Atharvan. Each of the four Vedas (Rig Veda, Sama Veda, Yajur Veda and Atharva veda) are divided further into four parts: Samhitas, the heart of the Vedas, comprises of hymns addressing deities and gods; Brahmanas, offer directions for conducting rituals; Aranyakas are treatises that the Brahmanas lean on - it is meant for hermits, and lastly the Aranyakas, explains mystical rites. Vedas are considered in Sanskrit as 'Apowrusheya', meaning no human being was involved in composing and compiling such high level of thoughts. Vedas are considered authentic flawless scriptures depicting in maxims and short phrases the significance of life on earth, knowledge of Astronomy, the purpose of human life and the relation of living entities with nature and the universe. They are seen as the way to understand all that is thinkable and imaginable. The Vedas's copious information is difficult to read and understand easily without the help of experienced scholars. Even a hundred life times is considered not enough to cover a full comprehension of the Vedas (Panduranga Rao, 2014).

\section{Upanishads 5}

According to Pattanaik (2016) "Upanishad technically means sit down and talk to me, like a discussion or a chat" (p.2). Specifically, the focus is on the atma - the soul,

5 The word Upanishad has been derived from the root words, sad, to which are added two prefixes: upa and ni. The prefix upa denotes nearness, and $n i$, totality. The root sad means to loosen, to attain and to annihilate. Thus, the etymological meaning of the word is knowledge, which when received from a competent teacher, loosens totally the bondage of the world, or surely enables the pupil to attain (i.e. realise) the self, or completely destroys ignorance, which is responsible for the deluding appearance of the infinite self as the finite embodied creature. From the introduction to 'The Upanishads' by Swami Nikhilanada (2013), Volume- One, from the Adviata Ashrama, Kolkata, India consciousness, essence and so on and so forth. The Upanishads consists of dialogues between masters and disciples interpreting philosophies and messages of the Vedas. The focus is mainly on the Atma, the soul, and consciousness (Roebuck, 2000). The Upanishads teach the truth-unknown to the sense organs- regarding living beings (Jivas) the universe (Jagat), and God (Isvara). They describe the nature and attributes of Bhahman, its reality and manifestations, powers and all aspects (Nikhilanada, 2008). They describe the creation, prese4rvation and ultimate dissolution of the universe and the changes and modifications of nature or Prakruti. Additionally, the Upanishads deal with the development of individual soul, its evolution and its bondage and its freedom (Nikhilanda,2008).

\section{Classification of Ancient Indian Spiritual Knowledge}

Two different trends can be identified in Indian spiritual knowledge, Shruti and Smriti. All that is heard by Rishis are called Shrutis. They are perfect without human involvement in writing, editing or commenting upon them. In other words, Vedas are taken as a premise in formal classical logical arguments, which is also referred to as shabda pramana.. The second to Shruti, is Smritis. These arose as not everybody had direct access to the Vedas, either through learning recitation or understanding their meanings. Smrithi's conveyed vedic meanings through epics like Ramayan, Mahabharath, and kalpa sutras. Ancient myths which are compiled from memory include the Puranas (legends). These fall under Smrithi.

\section{Central Embedded Philosophies}

Bhagavad-Gita is like a clear crystal, if you keep it on grass it appears to be emerald.

When the same crystal is kept on a red soil it looks like ruby and when held against the sky the same crystal appears like sapphire. Bhagavad-Gita reflects all three main schools of Vedanta, Dvaita, Advaita and Vishistadvaita vedantha. The three main proponents of these schools of philosophies wrote their own commentaries on Bhagavad-Gita, each demonstrating their schools of philosophies are embedded there.

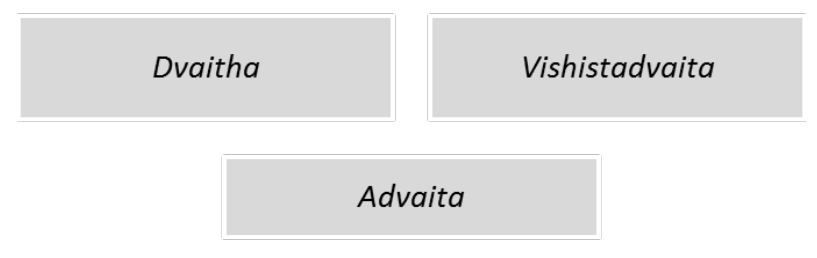

Advaita, Dvaitha and Vishistadvaita are prominent classic vedanta philosophies grounded by three great enlightened spiritual masters from southern part of India: 
Dwaita was founded by Madhvacharya (1238 - $1317 \mathrm{CE})$, Advaita by Shankara charya (788 - 820 AD) and Vishistadwaita by Ramanujacharya (1017 - 1137 CE) (Sri Ramakrishna Math, 2006).

\section{Dvaita Philosophy}

According to Dvaita, all living entities and the universe are separate from the higher being (God). Madhvacharya explained the connectivity or relations found in existence, comprises of five aspects: Soul and God, Soul and Soul, Soul and matter, God and Matter, and Matter to matter.

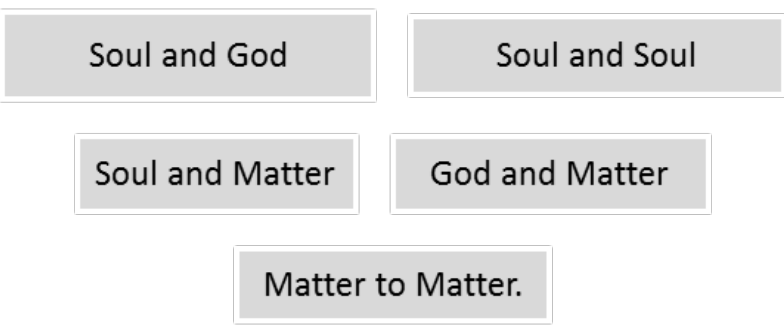

Vishnu is considered the Supreme Being, who dwells in Vaikunta with his consort Lakshmi. Soul is called Jeeva and in liberation, does not lose his individual identity through becoming one with the ultimate being Vishnu. Salvation here, is based on Bhakthi and Janana. Brahma Sutra Bhashya is one of Madhvacharya's classical works (Krishnamurthi, 2000)

\section{Vishistadvaita Philosophy}

Vishishtadvaita propounds that souls and the universe full of matter, are all real and Brahma's manifestation. Ramanuja Charya gives an analogy of a pomegranate, here its seeds are souls and the rind is the universe. One cannot think of the one without the other. The seeker of moksha can attain oneness with Vishnu the Higher Being but following this school of thought the seeker does not want to merge with Vishnu but continues to be close enjoying adorations and bhakti (Sri Ramakrishna Math, 2003).

The three foundational principles of Vishishtaadvaita Vedanta are:

Jiva (sentient beings), Jagat (non-sentient) and Vishnu, Narayana or Parabramhan.

Shri Bhashya produced the widely known work the Bramhasutras, as well as many other treaties.

\section{Advaita Philosophy}

According to Advaita the universe and all forms are unreal. Pure individual consciousness is real. As rivers merge in ocean so do individual souls eventually merge in Brahma, the Ultimate. Only proportions vary but the same cosmic light of consciousness dwells in each individual. Famous expression is 'Aham Brahmasmi' I am Brahma. One of the highlighted work of Sankaracharya is Gita Bhashya, which reflects his Advaita school of thought.

\section{In Summary}

The Bhagavad-Gita is an exceptional book without parallel. To obtain its full benefits, one has to not to only read it, but also practice its teachings in one's daily life. Indian spirituality is also unusual in that all three underlying philosophies are accepted and live side by side without followers of the various traditions trying to dominate the other. In this sense, tolerance and harmonious co-existence seem to be the basis of the Indian philosophic system, which also spills over into everyday life.

\section{REFERENCES}

Bhaktivedanta Swami Prabhupada, A.C. (2008) Bhagavad Gita As it is. London, UK: Bhaktivedanta Book Trust International Inc. ISBN 978-1-84599-049-7

Helliwell, J., Layard, R., \& Sachs, J. (2018). World Happiness Report 2018, New York: Sustainable Development Solutions Network

Krishnamurti, Sharma, B. N. (2000). A History of the Dvaita School of Vedānta and Its Literature, (3rd Ed.). Motilal Banarsidass (2008 Reprint). ISBN 978-8120815759.

Panduranga Rao, A. R. (2014) Srimad Bhagavatam, Sri Krishna Charitamrtam. Udupi, India: Tattwasamshodana Samasat. ISBN 978-93-81807-20-0

Pattanaik, Devdutt. (2015) My Gita. New Delhi, India: Rupa Publictions. ISBN 978-81-291-3770-8

Pattanaik, Devdutt. (2016) Devlok. Harayana, India: Penguin Books India. ISBN 978-0-143-42742-1

Radhakrishnan, S. (1974), Bhagavadgita, Blackie \& Son (India) Ltd,.Bombay

Roebuck, V. J. (2000). The Upanishads. Harayana, India: Penguin Books 2000. ISBN 978-0-14-044749-1

Sri Ramakrishna Math (2003). Thus Spake the Vedas. Chennai, India: Sri Ramakrishna Math Printing Press Mylapore. ISBN 81-7120-197-0

Sri Ramakrishna Math. (2006). Thus Spake Sri Krishna. Chennai, India: Sri Ramakrishna Math Printing Press Mylapore, ISBN 81-7823-379-7

Times Group Books (2015). Srimad Bhagavad Gita. New Delhi, India; Srinivas Fine Arts. ISBN 978-93-80942-68-1

Tandon, S. (2016). Exploring Well Being in Indian Context. Indian Anthropologist, 46(1), 63-78. Retrieved from http://www.jstor.org/stable/43899793

Yogi Ashokananda. (2015). The Power of Relaxation. London, United Kingdom: Watkins. ISBN 978-1-78028-714-0

Yadav, Yogacharya Dr Hansraj. (2009). Yoga Course For All. Mumbai, India: Bhartiya Vidya Bhavan ISBN 978-81-7276-421- 